\title{
Manipulaciones del fascismo portugués: diplomacia, censura y propaganda salazarista en la comunidad lusa de Estados Unidos 1
}

Alberto PENA-RODRÍGUEZ ${ }^{2}$

\begin{abstract}
Resumen:
Este trabajo es una aproximación a la acción política y propagandística desarrollada por el gobierno de la dictadura portuguesa en el seno de la comunidad de emigrantes lusos en los Estados Unidos de América durante los primeros años del Estado Novo y antes del inicio de la Segunda Guerra Mundial, entre 1933 y 1939. Mediante el análisis de documentación diplomática y fuentes hemerográficas de la colonia portuguesa en Norteamérica, el texto trata de mostrar cómo Salazar intentó controlar y manipular el discurso informativo y la imagen pública de su gobierno entre los emigrantes portugueses para representar una imagen benevolente de la dictadura en Portugal y evitar así un movimiento de disidencia política que pudiera tener un reflejo desestabilizador en Portugal.
\end{abstract}

Palabras clave:

Historia. Propaganda. Salazarismo. Estados Unidos. Emigrantes.

\section{Manipulações do fascismo português: diplomacia, censura e propaganda salazarista na comunidade lusa dos Estados Unidos}

\section{Resumo:}

Este trabalho é uma aproximação sobre a ação política e propagandística desenvolvida pelo governo da ditadura portuguesa na comunidade de emigrantes lusos nos Estados Unidos da América durante os primeros anos do Estado Novo e antes do início da Segunda Guerra Mundial, entre 1933 e 1939. Mediante análise de documentação diplomática e fontes hemerográficas da colônia portuguesa na América do Norte, o texto busca mostrar como Salazar tentou controlar e manipular o discurso informativo e a imagem pública de seu governo entre os emigrantes portugueses para representar uma imagen benevolente da ditadura em Portugal e evitar assim um movimento de dissidência política que poderia ter um reflexo desestabilizador em Portugal.

Palavras-chave:

História. Propaganda. Salazarismo. Estados Unidos. Emigrantes.

\section{Manipulations of the Portuguese fascism: diplomacy, censorship and salazarist propaganda in the United States Lusophone community}

\footnotetext{
Abstract:

This work is an approach to the political and propaganda action carried out by the Government of the Portuguese dictatorship in the heart of the community of Portuguese emigrants in the United States of America during the early years of the Estado Novo, and before the start of the Second World War, between 1933 and 1939. Through the analysis of diplomatic documentation and periodicals sources of the Portuguese colony in North America, the text tries to show how Salazar tried to control and manipulate informative speech and the public image of his Government among Portuguese emigrants to represent a

${ }^{1}$ Una versión de este trabajo, bajo el título de Ecos do fascismo português nos Estados Unidos. Os imigrantes portugueses e a instauração do Estado Novo: propaganda e contrapropaganda, fue presentado en el XI Encontro Nacional de História da Mídia, celebrado en la Universidade Presbiteriana Mackenzie (São Paulo), el 9 de junio de 2017.

${ }^{2}$ Doutor em Jornalismo pela Universidade Complutense de Madrid e em História pela UNED. Professor Titular de História da Propaganda na Universidade de Vigo (Espanha).E-mail: alberto@uvigo.es
} 
benevolent picture of the dictatorship in Portugal and thus avoiding a movement of political dissent that might have a destabilizing reflection in Portugal.

Keywords:

History. Propaganda. Salazarism. United States.Emigrants.

\section{Introducción}

Durante los primeros años de la dictadura portuguesa, entre 1926 y 1933, antes de la fundación del Estado Novo, sus estructuras institucionales no mostraron un especial interés en la comunidad emigrante al otro lado del Atlántico, al igual que sucedió con los gobiernos del período republicano. La prensa luso-americana se lamentaba con frecuencia de la falta de apoyo y atención de las autoridades nacionales con los portugueses que residían en Estados Unidos. Esta situación de lejanía institucional no se correspondía con la fuerte identificación emocional de los portugueses emigrados con su país y la cultura portuguesa, lo que acentuaba todavía más la sensación de abandono y olvido por parte de los responsables de la política nacional. A pesar del respeto que los emigrantes lusos sentían, en general, por sus agentes consulares debido a la gran significación simbólica que para ellos tenía representar a Portugal en Estados Unidos, las polémicas eran recurrentes en los medios impresos de la colonia como el Diario de Noticias o O Colonial. Los periódicos en portugués expresaban los lamentos y quejas que, en ocasiones, les hacían llegar los propios emigrantes portugueses cuando los servicios consulares eran deficientes o irregulares.

Dentro del contexto de la acción política que el gobierno portugués desarrolló hacia sus emigrantes en Norteamérica en los inicios del salazarismo en Portugal, este trabajo pretende aproximarse a la proyección que tuvo la dictadura entre los emigrados portugueses en Estados Unidos en los primeros años del Estado Novo, inaugurado oficialmente en 1933 tras la promulgación de sus Constitución Política, y durante los años de la Guerra Civil española, entre 1936 y 1939 (DE LA TORRE GÓMEZ; JIMÉNEZ REDONDO, 2013). Se ha estudiado con suficiente detalle el comportamiento político de los emigrantes portugueses en Brasil durante la dictadura (PAULO, 2000), pero se desconoce todavía la relación de Salazar con la comunidad lusa en territorio norteamericano. Mediante un análisis de la documentación diplomática y fuentes hemerográficas originales, con este trabajo se pretende conocer y analizar cuáles fueron las acciones de carácter diplomático adoptadas por el salazarismo para conseguir que la dictadura tuviese una recepción favorable por parte de la opinión pública 
emigrada en Norteamérica, así como la respuesta que dieron algunos emigrantes opositores al régimen.

La emigración portuguesa a Estados Unidos ha tenido históricamente una motivación esencialmente económica (PENA; MESQUITA; VICENTE, 2015; WILLIAMS, 2007; LEAL, 2007; GOULART, 2007; BAGANHA, 1990; PAP, 1981). A Norteamérica llegaron muy pocos exiliados políticos durante la dictadura salazarista. Sin embargo, el gobierno del Estado Novo intentó proyectar hacia sus emigrados la imagen de un Portugal renovado, con una afán modernizador y restaurador de un tradicionalismo conectado a la recuperación de una mentalidad imperial y de reinvención de un espíritu nacionalista cuyos valores patrióticos esenciales se identificaban con el perfil de Salazar, representado por la propaganda del régimen como un nuevo rey Afonso Henriques, fundador de la nación portuguesa. Para los portugueses emigrantes en Estados Unidos y sus descendientes no era fácil hacer compatible el ideario político de la dictadura, cuyas estructuras corporativas autoritarias, el control de la opinión pública y la represión política de la oposición lo convertían en un modelo antagónico al sistema de libertades civiles de la democracia americana. Por tanto, para muchos miembros de la comunidad luso-americana no fue fácil encontrar un encaje espiritual entre los valores políticos del Portugal de Salazar, que trató de convertirse en el catalizador de todas las virtudes de la nación portuguesa, y el país que les había dado una oportunidad para progresar. Sobre todo porque el Estado Novo trató de ocupar el lugar de la propia nación lusa a través de su discurso nacionalista exacerbado basado en la defensa de su imperio colonial, las raíces católicas y las tradiciones seculares vinculadas a un modo de vida rural, sencillo y austero que encajaba perfectamente con la representación pública de la figura política de Salazar (ROSAS, 2012; MATOS, 2010a, 2010b; MENEZES, 2009).

La comunidad emigrante portuguesa en Estados Unidos durante los años treinta era políticamente muy heterogénea. En 1930, el número de portugueses y lusoamericanos rondaba las 465.000 personas (PINA, 1945). En el seno de la comunidad, coexistían dos corrientes ideológicas preponderantes, una más conservadora y otra liberal y republicana, aunque ambas tenían una cierta permeabilidad política. No obstante, tanto la una como la otra compartían una misma identificación con los valores y la historia de la nación portuguesa, de los que se había apropiado la propaganda ultranacionalista del salazarismo. Por esta razón, muchos emigrantes adoptaron una 
actitud ambigüa respecto a la dictadura. El polo conservador, más próximo del salazarismo, agrupaba a un conjunto de visiones ideológicas en el que convivían posiciones opuestas al parlamentarismo democrático europeo, anti-republicanos, anticomunistas, católicos militantes y monárquicos (MENDONÇA, 2007; BARROW, 2002). El polo liberal, en cambio, aglutinaba a un amplio abanico de ideologías, más o menos progresistas, con una fuerte tendencia de izquierdas en el núcleo de New Bedford (Massachusetts), donde tenían su sede el Clube Republicano Portuguez y la Aliança Liberal Portuguesa, que eran entidades de tendencia progresista creadas para instruir a los emigrantes lusos. En esta órbita se situaban los republicanos, los izquierdistas (comunistas, socialistas y anarquistas), anticlericales, etc. que coincidieron en su frontal oposición a la dictadura. A grandes rasgos, sin embargo, ambos bloques convergían en la representación de un discurso político similar en las conmemoraciones patrióticas, que el Estado Novo siempre intentaba instrumentalizar para ganar adeptos (CORREIA, 2009).

Entre todas las ciudades en las que se registró algún tipo de actividad política y propagandística de cualquiera de los actores políticos implicados durante el Estado Novo, fue New Bedford la que cobró mayor protagonismo, particularmente durante el exilio del republicano de Educación João Camoesas, que se extendió hasta 1951, cuando fallece en Taunton (Mass.) (BANDEIRA, 1988). Allí, entre otras publicaciones en portugués, se editaba el influyente y popular Diario de Noticias, que era muy leído en los núcleos de población de la comunidad luso-americana en toda la costa Este, sobre todo en los Estados de Massachusetts, Nueva York y New Jersey.

Al principio, la instauración del Estado Novo en Portugal suscitó nuevas expectativas entre los emigrantes, con la esperanza de que el nuevo régimen entiendiera la importancia de conservar la cultura portuguesa en territorio norteamericano, una de cuyas mejores expresiones era la difusión de publicaciones periódicas en portugués. La dictadura había realizado algunos cambios en los consulados, como la destitución en 1929 de Abílio de Oliveira Águas en el consulado de Providence (Rhode Island) por desavenencias políticas. Pero la iniciativa más relevante fue el nombramiento del nuevo embajador en Washington, que sucedería al Visconde d'Alte, fallecido en 1933. La persona elegida para representar al Estado Novo en Estados Unidos fue el madeirense João António de Bianchi, un diplomático con una larga experiencia en diferentes legaciones de Portugal que según la narrativa de la propaganda oficial del régimen 
asumió su función de embajador de Salazar a bem de Portugal, frase que comunmente adornaba los informes de los diplomáticos del Estado Novo en los años treintra y cuarenta.

\section{Un nuevo embajador para el Estado Novo: João António de Bianchi (1933-1947)}

João António de Bianchi comenzó su carrera diplomática al servicio del Ministério de Negócios Estrangeiros en 1915. Fue jefe de la secretaría diplomática de Portugal durante la Conferencia de Paz de 1919, embajador de Portugal en Pekín, secretario de la embajada en Londres y Paris, y jefe de la división de Negócios Políticos del ministerio, en Lisboa. Poco después de ser nombrado, el nuevo embajador concedió una entrevista al reverendo y periodista José Cacella, publicada el 19 de septiembre de 1933 en el Diario de Noticias de New Bedford, en la que expresa su intención de conocer personalmente todas las colonias de portugueses en el país americano (CACELLA, 1933). En un mensaje dirigido a la comunidad portuguesa, João António Bianchi habla de la nueva situación de Portugal:

\footnotetext{
[...] Felizmente, o actual momento é propicio, pois a nossa reconstrução interna, em quanto outros se debatem com a grande crise, está feita com os recursos proprios, temos um orçamento equilibrado, e dinheiro disponível para fomento, para progresso social, beneficencia e demais necessidades nacionais, não temos desemprego e temos ordem. $E$ um momento histórico digno das nossas tradições a par da gloriosa época das nossas descobertas. [...] (CACELLA, 1933, p. 1, cursiva original).
}

José Cacella queda gratamente impresionado por João António Bianchi, para quien solicita la colaboración de toda la comunidad inmigrante lusa: "O seu plano de acção é magnífico", apunta el sacerdote en el texto de introducción del diplomático, que presentó sus credenciales ante el presidente de Estados Unidos, Franklin D. Roosevelt, en octubre de 1933. Posteriormente, Bianchi sería homenajeado en Nueva York en un acto organizado por el propio José Cacella y el cónsul general de Portugal, Victor Verdades de Faria. $^{3}$

La acción diplomática del nuevo embajador de Salazar tuvo una gran repercusión en la colonia. Por vez primera, un embajador de Portugal hizo lo que hasta entonces ningún otro diplomático luso había hecho: visitar a los emigrantes en sus principales colonias y mantener una relación estrecha con sus medios de comunicación para hacer llegar todos sus mensajes con más facilidad y eficacia. En este sentido,

\footnotetext{
${ }^{3}$ A las órdenes del Cónsul General en New York, el reverendo José Cacella presidió una comisión para organizar en New York el acto de homenaje y recepción del nuevo embajador, al que fueron invitadas todas las asociaciones gremiales de portugueses en Estados Unidos (JARDIM, 1933).
} 
Bianchi mejoró notablemente la imagen que los luso-americanos tenían del gobierno y de sus representantes diplomáticos. Al poco tiempo de establecerse en Washintgon, realizó viajes de varias semanas a Nueva Inglaterra (verano de 1934), y California (verano de 1935), ${ }^{4}$ que le permitieron convivir con sus compatriotas y recibir de ellos toda clase de honores. ${ }^{5}$ Fue tal la expectación y la repercusión del viaje de Bianchi a California, que se publicó una edición extraordinaria de un periódico, dirigido por João Marques Jardim, titulado Portugal na California, que informó monográficamente del periplo del diplomático luso por tierras californianas en septiembre de 1935, al tiempo que elogia las figuras de Carmona y Salazar. Cuando se anunció la visita del embajador a New Bedford, el Diario de Noticias saludó entusiásticamente los planes del diplomático publicando un editorial titulado "A visita do Ministro de Portugal", en el que reconoce su acierto y agradece esta iniciativa como una ocasión única para establecer un nuevo marco de colaboración entre la colonia y sus representantes consulares. Sus apariciones periodísticas en los medios de la comunidad se hicieron frecuentes, sobre todo en las fechas en las que había alguna celebración conmemorativa, como el día de la independencia de Portugal, el $1^{\circ}$ de diciembre, cuya efeméride promovió con estrategia política. ${ }^{6}$ Cada año, João A. Bianchi y los miembros del equipo consular acudían a algún acto institucional o enviaban un comunicado oficial a los programas de radio portugueses y a la prensa luso-americana (NÚMERO..., 1940; BIANCHI, 1936).

En poco tiempo, el nuevo embajador no sólo consiguió darse a conocer, sino que elevó su prestigio y notoriedad. Durante el tiempo que permaneció en Estados Unidos, João António de Bianchi ejerció una fuerte influencia en la colonia. A pesar de ser un diplomático de carrera que actuaba con prudencia y cautela, Bianchi no era ajeno a la acción política de su gobierno. Se prestó a realizar campañas que incrementaran el prestigio del Estado Novo a través de una relación estrecha con algunos medios de comunicación luso-americanos, en particular con el Diario de Noticias. Cuando, en

\footnotetext{
${ }^{4}$ El viaje a California se inició el 24 de julio de 1935. El embajador, que viajó en automóvil acompañado de su esposa, Clara de Bianchi, hizo durante el trayecto varias paradas en lugares con presencia portuguesa. João António de Bianchi participó en las fiestas de la colonia en San Francisco, entre el 7 y el 14 de septiembre, y fue huésped de la Exposición Internacional de San Diego, donde presidió un acto en honor del navegante portugués Rodrigues Cabrilho (AHD. Embajada de Portugal en Washington. Caja ${ }^{\circ}$ 37. Nota enviada por la embajada "aos jornais de Nova Inglaterra e New York", 25 de julio de 1935). La visita del diplomático a Nueva Inglaterra se extendió entre julio y septiembre de 1934.

${ }^{5}$ AHD. Embajada de Portugal en Washington. Carpeta ${ }^{\circ}{ }^{\circ}$ 15. Informes diversos de los viajes realizados por João António de Bianchi a las colonias luso-americanas durante 1934 y 1935.

${ }^{6}$ AHD. Embajada de Portugal en Washington. Caja no 37 . Oficio del embajador de Portugal en EE.UU. al ministro de Negócios Estrangeiros, 18 de diciembre de 1936.
} 
junio de 1947, fue relevado por Pedro Teotónio Pereira, que procedía de la legación de Brasil (y que antes había sido el representante de Salazar ante el general Franco), fue despedido con honores por la prensa de la colonia, que agradeció su gestión al frente de la representación diplomática de Portugal en EE.UU (TEIXEIRA, 1947; A VIAGEM..., 1948). Poco antes de incorporarse a su nuevo puesto como secretario general del Ministério de Negócios Estrangeiros, en Lisboa, la comunidad luso-americana realizó el 27 de julio de 1947 un acto de homenaje en su honor en el hotel Waldorf Astoria de Nueva York, durante el cual se le hizo entrega de un retrato pintado por Henrique Medina (O EMBAIXADOR..., 1947). Consciente de la eficacia en la estrategia de Relaciones Públicas seguida por J. A. Bianchi, Pedro T. Pereira imitaría desde el principio algunas de sus acciones, como la visita a las principales colonias de inmigrantes, para mostrar la misma cercanía y disponibilidad oficial (O SENHOR..., 1948).

\section{Las inquietudes de Salazar ante la acción de los opositores en Estados Unidos}

Cuando João António de Bianchi asumió su nuevo puesto como embajador de Portugal en Estados Unidos, hubo de enfrentarse a la actividad creciente de los opositores al régimen salazarista. Aunque en febrero de 1938 Bianchi restó importancia ante el gobierno portugués a las acciones de propaganda del exministro João Camoesas, que se exilió en Estados Unidos en 1929, calificando sus campañas "de consequencias muito limitadas", 7 durante sus primeros años en Washington el jefe de la legación portuguesa en Washington se vio obligado a desarrollar estrategias de comunicación pública para tratar de contener o mitigar los efectos de la propaganda anti-fascista y anti-salazarista en EE.UU. a instancias del propio António de Oliviera Salazar, que se ocupó personalmente de la cartera de Negócios Estrangeiros entre noviembre de 1936 y febrero de $1947 .{ }^{8}$ En un telegrama enviado el 24 de mayo de 1935, Salazar le expresa a Bianchi su preocupación por la intensidad creciente de las campañas de prensa de la Aliança Liberal Portuguesa (ALP) de New Bedford, “[...] que distribui manifestos com refalsadas mentiras sobre o Estado Novo e que convem contra bater [...]”, exponía el

\footnotetext{
${ }^{7}$ AHD. Embajada de Portugal en Washington. Caja n ${ }^{\circ} 13$. Oficio n ${ }^{\circ} 65$, proc. 1/38, de João A. de Bianchi al ministro de Negócios Estrangeiros, 20 de febrero de 1938.

${ }^{8}$ AHD. Telegrama confidencial $n^{\circ} 10$ enviado por el ministro de Negócios Estrangeiros al embajador de Portugal en Washington, 24 de mayo de 1935.
} 
dictador portugués. ${ }^{9}$ Sin embargo, el embajador era partidario de adoptar una posición cautelosa, pues la libertad de expresión, el debate y la crítica abierta en Estados Unidos no eran propicios para un formato de campañas como las que se desarrollaban en Portugal, donde el gobierno de la dictadura podía impedir cualquier acción opositora a través de la censura y la policía política. Por esta razón, el embajador le envía un telegrama a Salazar el 27 de mayo respondiéndole que la cuestión “[...] é melindrosa, receio efeitos contraproducentes e embaraçosos." 10

Pero Salazar estaba realmente preocupado con los posibles efectos de los mensajes propagandísticos de sus opositores en Norteamérica, y ordena ser informado de "[...] todas as comunicações em forma de cartas, folhetos, impressos clandestinos e meios semelhantes contendo matéria ofensiva ou agressiva contra a actual situação política em Portugal e seus homens públicos". ${ }^{11}$ El gobernante solicita incluso a su embajador la elaboración de un informe confidencial sobre el cónsul general en Nueva York, Victor Verdades de Faria, del que tenía informaciones que lo vinculaban con la difusión de uno de los manifiestos de la ALP. ${ }^{12}$ Asunto que João de Bianchi atribuye a una calumnia, pues el cónsul "[...] tem defendido calorosamente o conhecimento detalhado perante a Colonia e perante os estrangeiros obra do Governo [...]", argumenta. $^{13}$

En respuesta a un telegrama de Salazar, en el que le pide que preste todo tipo de ayuda al periódico A Patria de New Bedford, João A. de Bianchi remite un oficio el 10 de junio de 1936 en el que explica al dictador cuál es la situación de la "periclitante imprensa" portuguesa de la costa atlántica. ${ }^{14}$ El embajador trata de apaciguar la inquietud de Salazar sobre las campañas adversas a su política, explicando en tono peyorativo que este tipo de prensa no debía preocupar demasiado al gobierno portugués:

[...] Todos estes jornalecos são uma especulação e um negociosinho, muitas vez de ocasião (sic), dos seus proprietários, redactores, editores, tres pessoas distinctas (sic) incorporadas no mesmo individuo, que mendiga, adula, intriga e ameaça para obter anunciosinhos e assinaturas, e, de borla ou a trôco de inserções sem resultados nas suas folhas, consegue alguns fornecimentos, objectos, mercearias e serviços. [...] (AHD. Embajada de Portugal

\footnotetext{
${ }^{9}$ AHD. Telegrama confidencial $\mathrm{n}^{\mathbf{0}} 10$ enviado por el ministro de Negócios Estrangeiros al embajador de Portugal en Washington, 24 de mayo de 1935.

${ }^{10}$ AHD. Telegrama confidencial $\mathrm{n}^{\circ} 23$ del embajador de Portugal en Washington al ministro de Negócios Estrangeiros, 27 de mayo de 1935.

${ }^{11}$ AHD. Circular $\mathrm{n}^{\mathrm{o}} 155$ enviada por el embajador de Portugal en Washington al cónsul general en New York, (sin datar) (1935).

${ }^{12}$ AHD. Telegrama confidencial $n^{\circ} 10$ del ministro de Negócios Estrangeiros al embajador de Portugal en Washington, 24 de mayo de 1935.

${ }^{13}$ AHD. Telegrama confidencial $n^{\circ} 22$ del embajador de Portugal en Washington al ministro de Negócios Estrangeiros, 26 de mayo de 1935.

${ }^{14}$ Expresión del embajador de Portugal (AHD. Embajada de Portugal en Washington. Caja no 37, carpeta $\mathrm{n}^{\circ}$ 150. Oficio del embajador de Portugal a Oliveira Salazar, 10 de junio de 1936).
} 
en Washington. Caja $\mathrm{n}^{\circ} 37$, carpeta $\mathrm{n}^{\circ} 150$. Oficio del embajador de Portugal a Oliveira Salazar, 10 de junio de 1936).

João António de Bianchi expresa que, entre todos los periódicos de la comunidad luso-americana, el más relevante es el Diario de Noticias, “[...] com circulação muito superior aos outros, não só porque é diario, mas porque é mais noticioso [...]”. Destaca también el semanario católico Novidades, por su afinidad al Estado Novo, aunque de difusión escasa.Sobre A Patria, informa a Salazar que su director, Carlos Supico, era uno de los líderes de la colonia madeirense. Pero le dice que el periódico era editado de forma irregular y no lo veía capaz de remontar la situación. ${ }^{15}$

Probablemente, por la resonancia que tenía la ciudad de Nueva York, donde estaba la sede de muchas organizaciones políticas internacionales y medios de comunicación de gran impacto informativo, el gobierno portugués tuvo una especial sensibilidad sobre lo que ocurría en el entorno de la colonia en aquella área. A requerimiento de la embajada, el cónsul envió el 23 de mayo de 1935 un memorándumtitulado "Campanhas políticas nos Estados sob a jurisdicção do Consulado Geral de Portugal en Nova York contra o Governo português". En este informe, el cónsul explica que jamás hubo ninguna crítica al salazarismo en los medios de la colonia desde su llegada a finales de 1927.

Sin embargo, la situación se complicó a partir de 1936, cuando la agitación política de los exiliados y las campañas de la ALP, que adoctrinaba a los inmigrantes contra la dictadura, alcanzaron una mayor difusión nacional e internacional. En agosto de aquel año, con la Guerra Civil española como telón de fondo, causó inquietud la circulación en Estados Unidos del periódico Portugal Republicano, el portavoz de los exiliados políticos portugueses en Brasil, ${ }^{16}$ y el panfleto The Dictatorship in Portugal, editado por el International Commiteee for Political Prisoners, con material proporcionado por los opositores. ${ }^{17}$ Además, la ALP comenzó a distribuir Unir, el portavoz de los exiliados portugueses en Francia. ${ }^{18}$ Y en New York aparecerían también nuevas publicaciones anti-fascistas, como $O$ Bacamarte, A Plebe y La Voz, este último con edición en español y portugués. Además, algunos periódicos importantes de la

\footnotetext{
15 AHD. Embajada de Portugal en Washington. Caja $n^{\circ} 37$, carpeta $n^{\circ} 150$. Oficio del embajador de Portugal a Oliveira Salazar, 10 de junio de 1936.

16 AHD. Caja $n^{\circ} 13$. Véanse varios oficios y telegramas relacionados con la circulación del periódico Portugal Republicano en EE.UU., agosto de 1936.

${ }_{17}$ AHD. Informes relacionados con el panfleto The Dictatorship in Portugal.

${ }^{18}$ AHD. Oficio n 55 del cónsul de Portugal en New Bedford al encargado de Negocios de la embajada, João de Deus Ramos, 23 de julio de 1937.
} 
colonia en la costa Este, como el Diario de Noticias y $O$ Colonial, se habían convertido en plataformas de propaganda del anti-salazarismo.

\section{La reacción política del Estado Novo: diplomacia, censura y propaganda}

El Estado Novo reaccionó a la ofensiva de sus enemigos con diversas acciones coordinadas por el Secretariado de Propaganda Nacional (SPN), que actuó en diversos frentes: incrementando la producción y difusión de materiales propagandísticos en EE.UU.; ${ }^{19}$ presionando de forma directa e institucional, desde el SPN o a través de los servicos consulares, a los editores de los periódicos luso-americanos y norteamericanos para impedir la publicación de artículos adversos; ${ }^{20}$ publicando textos escritos por el propio personal diplomático; subsidiando los periódicos favorables; y promoviendo o participando en actividades que contribuyeran a prestigiar el Estado Novo mediante la cobertura periodística en los medios de comunicación estadounidenses. ${ }^{21}$

Uno de los episodios que revela el apasionamiento y la intensidad de la lucha entre los partidarios y los detractores de la dictadura en Estados Unidos, lo protagonizó António Eça de Queiroz, subdirector del SPN e hijo del famoso escritor del realismo portugués. Eça de Queiroz se enfrentó públicamente con Manuel Moutinho, cofundador y secretario de la ALP, uno de los más activos propagandistas contra el Estado Novo y aliado de João Camoesas en la campaña contra el salazarismo desde Nueva Inglaterra. ${ }^{22}$ Manuel Moutinho fue el autor de una serie de artículos anti-salazaristas publicados en $O$ Colonial que irritarían profundamente al gobierno portugués. El subdirector del SPN dirigió al propietario y director de $O$ Colonial, el madeirense Frederico da Costa, una carta datada en Lisboa el 20 de agosto de 1935, para expresarle su malestar por la publicación de las informaciones y los artículos de Manuel Moutinho, que acusaban al gobierno portugués de torturar a los presos políticos. No era la primera vez que António Eça de Queiroz se quejaba al director de $O$ Colonial. El 30 de marzo del mismo año, el subdirector del SPN le recordó a Frederico da Costa el "deber" que

\footnotetext{
19 AHD. Caja $\mathrm{n}^{\text {o }}$ 18. Oficio $\mathrm{n}^{\circ} 960$ (proc. 9/38) del embajador de Portugal al ministro de Negócios Estrangeiros solicitando materiales propagandísticos para difundir EE.UU., 31 de octubre de 1938.

${ }^{20}$ ANTT. AOS/SGPCM-GPM, caja $\mathrm{n}^{\circ}$ 5, PC-156, 3, $\mathrm{n}^{\circ} 4$. Oficio $\mathrm{n}^{\circ} 1273$ del subdirector del Secretariado de Propaganda Nacional, António Eça de Queiroz, al Presidente do Conselho de Ministros, 19 de septiembre de 1938, informando sobre las presiones ejercidas sobre varios periódicos luso-americanos.

21 AHD. Embajada de Portugal en Washington. Caja $n^{\circ}$ 36. Documentación diversa sobre la Festa da Raça, organizada en New Bedford por una comisión supervisada por el embajador, entre el 13 y el 18 de junio de 1939.

${ }^{22}$ Véanse, por ejemplo: Moutinho (1937a, 1937b, 1937c, 1938a, 1938b, 1938c).
} 
tenían los periódicos portugueses en el extranjero de "defender e elevar o bom nome de Portugal". 23

En su misiva fechada el 20 de agosto de 1935 y publicada en $O$ Colonial el 6 de septiembre de aquel año, António Eça de Queiroz rebate las acusaciones contra su gobierno argumentando que las libertades en Portugal son "larguíssimas"; y afirmando incluso que los adversarios del Estado Novo pueden expresarse libremente (UMA CARTA..., 1935, p. 1-2). Y contraataca denunciando que él sí sufrió la persecución política y el maltrato del régimen republicano. Muestra también su enfado por la manera en que Manuel Moutinho describe al Estado Novo y sus líderes, atribuyéndole la cobardía de hacerlo desde el otro lado del Atlántico, "a 6000 kilómetros de distância" (UMA CARTA..., 1935, p. 1-2). “[...] O sr. Manuel Moutinho não honra o jornal em que escreve; suja-o indelevelmente, rebaixa-o, usando de processos e duma fôrma que desde logo, pela sua violência e torpeza, repelem o leitor de bom gosto [....]", señala Eça de Queiroz (UMA CARTA..., 1935, p. 1-2). El subdirector del SPN escribió también una misiva personal al secretario de la ALP. En ella, con una lenguaje ofensivo e insultante, lo acusa de traicionar cobardemente a su patria, incluso con una velada amenaza final, "o mundo é pequeno Snr. Moutinho [...]”.

Manuel Moutinho aprovechó esta amenazante epístola del subdirector del SPN como una prueba de la eficacia de su propaganda y de la preocupación de la dictadura por las campañas anti-salazaristas en la prensa inmigrante portuguesa. El secretario de la ALP publicó una réplica a Eça de Queiroz en $O$ Colonial,y avivó la polémica difundiendo un nuevo manifiesto en octubre de 1935 titulado A Autópsia dum Imbécil, con una tirada de 5000 ejemplares. En su respuesta, Manuel Moutinho descalifica al dirigente salazarista, al que llama "cérebro doente", "apaniguado", "abôrto acéfalo", “cretino", entre otras lindezas (A AUTÓPSIA..., 1935). El subdirector del SPN ejerció también fuertes presiones sobre el propietario del Diario de Noticias, Guilherme Machado Luiz,para evitar que João Camoesas siguiese publicando en su periódico artículos contra la dictadura. ${ }^{24}$ Propósito que Eça de Queiroz acabó consiguiendo en agosto de $1938 .^{25}$

\footnotetext{
23 "Nota Oficiosa da Presidência do Conselho ao "Colonial"'. O Colonial, 19 de abril de 1935. AHD. Embajada de Portugal en Washington. Caja $\mathrm{n}^{\circ}$ 37. (Recortes de prensa luso-americana).

${ }^{24}$ ANTT/AOS, SGPCM-GPM, caja $\mathrm{n}^{\circ} 5$, PC-156, 3, $\mathrm{n}^{\circ} 4$. Oficio $\mathrm{n}^{\circ} 1273$ del subdirector del Secretariado de Propaganda Nacional, António Eça de Queiroz, al Presidente do Conselho de Ministros, 19 de septiembre de 1938.

${ }_{25}$ AHD. Embajada de Portugal en Washington. Caja no 37. Carta enviada por João Camoesas a Guilherme M. Luiz, 19 de agosto de 1938.
} 
La presión que ejerció el SPN sobre la prensa luso-americana redujo la intensidad de la propaganda anti-salazarista, especialmente después de la victoria del general Franco en España, lo que provocó una cierta desazón y frustración entre los opositores al fascismo luso, que no fundarían el Portuguese-American Committee for Democracy hasta 1945, bajo el liderazgo de João Camoesas, José Rodrigues Miguéis y Abílio de Oliveira Águas.

\section{"The prophet of a New Order": La propaganda salazarista en Estados Unidos}

Entre las campañas organizadas por propaganda salazarista para limitar los efectos de la oposición política en Estados Unidos, se pueden destacar tres casos paradigmáticos: el nombramiento el 15 de junio de 1938 de António de Oliveira Salazar como DoctorHonoris Causa por la Fordham University, una de las instituciones universitarias de gran prestigio entre la elite católica norteamericana; la construcción del pabellón de Portugal en la World's Fair de New York, celebrada entre abril y octubre de 1939;y la participación oficial en la Golden Gate International Exposition de San Francisco, desarrollada entre 1939 y $1940 .{ }^{26}$ Estos tres eventos tuvieron una gran repercusión en las páginas de la prensa emigrante portuguesa, identificada con el liderazgo de Salazar por su reconocimiento entre la elite académica, política y comercial estadounidense.

Con el doctorado Honoris Causa, la Fordham University pretendía reconocer los méritos políticos de António de Oliveira Salazar, al que describe como el restaurador de la patria portuguesa, creador de un nuevo Estado inspirado por los principios del Pontificado Romano y "profhet of a new order". En el acto que convirtió a Salazar en el primer Honoris Causa extranjero por la universidad neoyorquina, el dictador fue representado por el embajador João António de Bianchi, que habló también en nombre de la comunidad portuguesa que residía en Estados Unidos. ${ }^{27}$ En su crónica para el Diario de Noticias, Vasco de Sousa Jardim destaca el prestigio adquirido por su país en Norteamérica gracias al reconocimiento académico de la Fordham University, en un concurrido acto al que acudieron más de 5000 personas.

\footnotetext{
${ }^{26}$ El gobierno portugués inauguró también un pabellón propio durante la Golden Gate International Exposition de San Francisco, celebrada entre el 18 de febrero y el 29 de octubre de 1939, y el 25 de mayo y 29 de septiembre de 1940. El 16 de junio de 1939, fue el Dia de Portugal en esta exposición, pensada para promocionar la bahia de San Francisco, que había puesto en funcionamiento el puente del Golden Gate en 1937.

${ }^{27}$ La documentación completa sobre el Doctorado Honoris Causa por la Fordham University de New York puede leerse en: AHD. Embajada de Portugal en Washington. Caja n ${ }^{\circ} 29$. También hay información complementaria en la caja ${ }^{\circ} 18$, proc. $n^{\circ} 9$.
} 
La campaña realizada por el SPN entre 1939 y 1940 en Estados Unidos durante su participación en la World's Fair de Nueva York y la Golden Gate International Exposition de San Francisco, consiguió difundir una imagen de modernidad (PORTUGAL..., 1939). El gobierno portugués insistió en la idea de que el nuevo Portugal de Salazar se basaba en un proyecto político que pretendía restaurar el pasado glorioso del país, con vocación imperial, tradicionalista y vanguardista al mismo tiempo, inspirado en la visión de un líder irrepetible, legitimado por su condición de profesor en Coimbra, que había sido entronizado por la propaganda del régimen como una especie de salvador de la nación. Su "invulgar talento", según un sesudo artículo publicado por el salazarista M. Macedo en enero de 1933 en el Diario de Noticias, había conseguido equilibrar milagrosamente las cuentas del país (MACEDO, 1933, p. 7).

A instancias de António Ferro, durante el día de Portugal en la exposición internacional de Nueva York, el 17 de julio de 1939, Salazar dirigió a la colonia portuguesa un mensaje radiofónico como señal de su compromiso con los emigrantes luso-americanos (DISCURSO..., 1939).El discurso radiofónico del jefe del gobierno tuvo una gran repercusión en la prensa portuguesa en Estados Unidos. Nunca antes un gobernante del país se había dirigido directamente a los emigrantes portugueses. Con el título Mensagem do Doutor Oliviera Salazar aos Portugueses na America, tanto el Jornal Português como el Diario de Noticias reproducen el breve discurso del dictador luso (MENSAGEM..., 1939a, 1939b). En su alocución, Salazar rememora las figuras de los navegantes João Rodrigues Cabrilho y Miguel Corte Real y reivindica el nuevo resurgimiento de Portugal.

El discurso radiofónico de Salazar fue cordialmente saludado por un sector de la colonia, que le hizo llegar un mensaje de agradecimiento en agosto de $1939 .^{28}$ El Diario de Noticias publicaría un extenso artículo en el que destaca el esfuerzo propagandístico del director del SPN, António Ferro, y del gobierno portugués, en su afán por mejorar la situación de la colonia y extender una imagen positiva de Portugal en Estados Unidos (A IMPORTANTE..., 1939).

El liderazgo de Salazar estaba avalado, además, por intelectuales reputados que colaboraban con él, como los máximos representantes del SPN, António Ferro o António Eça de Queiroz, que estaban a sus órdenes con la misión de "iluminar ao mundo" (FERRO, 1946, p. 16). Este fue el eje de la propaganda de Portugal en la

\footnotetext{
${ }^{28}$ ANTT. AOS/SGGM-GPM, caja no 20, PC-231. Oficio no 3836 del Chefe de Serviços (interino), Silva Dias, al Chefe de Gabinete do Presidente do Conselho, 12 de agosto de 1939.
} 
exposición de Nueva York, cuyo pabellón contenía en el hall de entrada dos grandes estatuas de Salazar (vestido con el traje académico de la Universidad de Coimbra, realizada por el escultor Francisco Franco) y el general Carmona.

Las figuras políticas de Salazar y Carmona fueron reconocidas por algunos inmigrantes mediante la creación de sendas asociaciones dedicadas a la promoción pública de ambos líderes en EE.UU. El jefe del Estado portugués contó con el apoyo del llamado Club Português General Carmona, con sede en New Bedford, mientras que Salazar fue honrado por el Portuguese-American Salazar Club, fundado en mayo de 1933 en Lawrence (Mass.), que llegó a tener más de 600 socios durante sus veinte años de existencia. ${ }^{29}$ La admiración popular hacia Salazar y Carmona era también el reflejo de la devoción que algunos periodistas portugueses mostraban por ambos o por alguno de ellos en las páginas de la prensa luso-americana. Como ejemplo simbólico, se podría citar a J. C. Valim, quien en un artículo publicado el 25 de enero de 1937 en A União Portuguesa de California, bajo el título Salazar, O Grande, expresó cuáles eran, según él, las principales virtudes del jefe del régimen fascista luso, al que describe como "[...] um dos mais competentes financeiros do mundo, mas ainda um político sagaz e habilíssimo, um patriota no mais alto grau e um dos maiores homens de Estado que tem dirigido os destinos da nação portuguesa [...]” (VALIM, 1937, p. 1).

\section{El viaje triunfal del director del SPN, António Ferro}

El comisario general de la World's Fair de N. York y la Golden Gate International Exposition de San Francisco fue el director del SPN, António Ferro. El cerebro de la propaganda del régimen portugués llegó a bordo del buque "Saturnia" (de la Italian Line) al puerto neoyorkino el 12 de abril de 1939, acompañado por su secretario Guilherme Pereira de Carvalho (CHEGADA..., 1939, p. 1). Durante los casi tres meses que António Ferro estuvo en Estados Unidos, fueron muchas las ocasiones en las que hizo promoción del Estado Novo, tanto en la costa Este como Oeste. Su actividad propagandística le reportó una gran popularidad, hasta el punto de que diversas instituciones de emigrantes de Connecticut, Pennsylvania, Nueva York y New Jersey se pondrían de acuerdo para organizar un homenaje público el 10 de julio de

\footnotetext{
${ }^{29}$ ANTT. AOS/CO/PC-56, caja $\mathrm{n}^{\circ}$ 632. Véase la siguiente documentación: oficio del presidente del Portuguese-American Salazar Club, Inc. a António de Oliveira Salazar, del 24 de abril de 1957; telegrama $\mathrm{n}^{\circ} 1749$ del secretario general del Minsitério dos Negócios Estrangeiros al consulado de Portugal en Boston, s. f.; y telegrama n 2354 del cónsul en Boston al Ministério dos Negócios Estrangeiros, 15 de mayo de 1957.
} 
1939 en su honor antes de que partiese hacia Lisboa a bordo del vapor "Normandie" una semana después (HOMENAGEM..., 1939, p. 1). Durante este acto, además, se le hizo entrega del "Mensagem de Gratidão" de los inmigrantes portugueses dirigido a Salazar por el extraordinario prestigio alcanzado por Portugal durante la participación en la feria neoyorquina que el dictador agradeció de forma expresa y pública en septiembre de 1939 (O DR. OLIVEIRA..., 1939, p. 1).

La campaña desarrollada por el director del SPN tuvo un gran impacto también en la línea editorial de los periódicos luso-americanos más relevantes, que reconocieron y elogiaron su contacto directo con los inmigrantes. Ferro realizó diversos viajes a los principales núcleos de la colonia para divulgar los logros del régimen fascista portugués. Una de sus primeras acciones propagandísticas en California, a donde viajó a principios de julio de 1939, fue la presentación y distribución, en el stand de Portugal en la feria de San Francisco, de un opúsculo de su autoría titulado Salazar, Portugal e o seu Chefe (ANTONIO..., 1939). Para la World's Fair de Nueva York, Ferro preparó ex profeso otro libro, dedicado a promocionar las virtudes del nuevo Portugal, su economía y sus líderes. Se trataba de una obra conmemorativa de carácter propagandístico, titulada Portugal in New York World's Fair 1939, con textos y fotografías del general Carmona, del cardenal patriarca de Lisboa y del propio Salazar, cuyos contenidos y estructura, organizado por Marques da Costa, con la colaboración artística de Celestino Soares, Ferreira Gomes y Roberto de Araújo (COSTA, 1939). ${ }^{30}$ El SPN editaría también un volumen sobre la exposición de San Francisco, firmada por Celestino Soares, titulada California and the Portuguese. How the Portuguese helped to build up California: a monograph written for the Golden Gate International Exposition on San Francisco Bay 1939 (SOARES, 1939).

En las alocuciones públicas de António Ferro en Estados Unidos, muy difundidas por la prensa luso-americana, los elogios a Salazar y los avances del Estado Novo eran un tema recurrente, insistiendo particularmente en que la política del gobierno portugués, una vez "arrumada a casa", prestaría especial atención a sus emigrantes en América (DISCURSO..., 1939b, 1939c). Ferro logró extender la percepción de que Portugal estaba de "moda" en el mundo (SILVA, 1940), y que Salazar era el "homem do momento", según la expresión del Jornal Português de Oakland (SALAZAR..., 1941, p. 1). En su discurso de inauguración del pabellón portugués en la World's Fair, el 8 de mayo de 1939, António Ferroaprovechó la

\footnotetext{
${ }^{30}$ Un ejemplar de este libro se encuentra en la Freitas Library.
} 
oportunidad para trazar ante el público americano el perfil de Salazar como el de un político con visión de futuro, moderno e innovador. Salazar, según Ferro, era una especie de mesías, pues pertenecía a la "raça dos descobridores". ${ }^{31}$ António Ferro también pronunció un discurso sobre la nueva política de Salazar hacia los emigrantes en Estados Unidos en la celebración del Día de Portugal en la World's Fair neoyorquina (DISCURSO..., 1939a). El director del SPN, consciente del malestar de la colonia por el distanciamiento y la indiferencia crónica de los gobiernos portugueses, aborda la cuestión prometiendo el fin de las políticas de olvido y abandono. Según su argumentación, el Estado Novo se ocupó primero de arreglar la situación política y económica en un contexto nacional. Ahora, el gobierno portugués orientaría su ayuda hacia los "portugueses da saudade", contraponiendo la etapa de indiferencia absoluta de los gobiernos republicanos al resurgimiento de Portugal tras el golpe del 28 de mayo de 1926 (DISCURSO..., 1939a, p. 4). António Ferro utiliza la participación de Portugal en las exposiciones internacionales de New York y San Francisco como una prueba de que los tiempos han cambiado, de que el gobierno de Portugal quería establecer una relación más estrecha con la comunidad portuguesa en Estados Unidos.Para garantizar el contacto permanente del Estado Novo con los inmigrantes portugueses en Estados Unidos, el director del SPN informa de la próxima apertura de una Casa de Portugal en Nueva York, que se ocuparía de promover campañas de propaganda sobre el nuevo Portugal. Esta institución comenzó a funcionar en enero de 1941, con sede en el Rockefeller Center y un presupuesto anual de 40.000\$. La dictadura portuguesa utilizaría esta Casa de Portugal en Manhattan como una plataforma de acción propagandística en Estados Unidos, tanto para difundir el discurso salazarista entre los emigrantes como para proyectar la imagen de un Portugal en la vanguardia política, social y cultural. Sin embargo, la coyuntura política internacional, desfavorable en Norteamérica a los regímenes de corte fascista durante y después de la Segunda Guerra mundial, provocaron el distanciamiento e interés del Estado Novo por la comunidad inmigrante luso-americana. Esta volvería a sentirse huérfana de su gobierno después de la cercanía diplomática y propagandística mostrada durante los primeros años de la dictadura, que había conseguido que muchos emigrantes viesen a Salazar como un auténtico héroe del resurgimiento portugués.

\footnotetext{
${ }^{31}$ ANTT. AOS/CO/PC-12D, caja n ${ }^{\circ}$ 661. "Discurso pronunciado pelo Excelentissimo Senhor Antonio Ferro, Comisário Geral de Portugal na Exposição Internacional de New York”.
} 


\section{Conclusiones}

Desde el inicio del Estado Novo, el salazarismo mostró un especial empeño en crear una imagen favorable en la opinión pública internacional. Además de las campañas de propaganda específicas para aumentar o prestigio exterior de Salazar, el régimen salazarista desarrolló una dinámica política para influir en el imaginario político y cultural de los emigrantes. Con esta estrategia, la dictadura pretendía dominar la representación simbólica del Estado Novo y su percepción ideológica en los países con núcleos de emigración portuguesa. Uno de los casos paradigmáticos sobre la propaganda política y el control ideológico del salazarismo en la emigración, es el caso de la comunidad portuguesa en los Estados Unidos entre 1933 y 1940, un período especialmente relevante para la consolidación de la dictadura en Portugal, con el movimiento republicano luso muy activo en exterior y el telón de fondo de la Guerra Civil española.

En las principales ciudades norteamericanas donde había población portuguesa, Salazar utilizó sus estructuras y recursos diplomáticos, así como las redes institucionales y los medios de comunicación de los emigrantes, para intentar someter al control ideológico a los portugueses. El salazarismo aplicó la censura, presionó a editores de periódicos, organizó y participó en numerosas actividades institucionales y boicoteó actos públicos contra el fascismo en EE.UU. El objetivo esencial de esta estrategia política internacional era frenar cualquier tipo de reacción de los emigrantes que pudiese prejudicar la imagen del Estado Novo y su gobierno. Salazar temía, sobre todo, que las campañas de los opositores en Estados Unidos, liderados por el exministro republicano João Camoesas, pudieran tener algún tipo de impacto o reflejo revolucionario en Portugal. Pero también que los mensajes propagandísticos antisalazaristas llegaran a ejercer influencia sobre el gobierno norteamericano y que aquél se sintiera obligado a aplicar algún tipo de presión contra la dictadura portuguesa en su política exterior.

A través de su embajada en Washington y las diferentes sedes consulares, en coordinación con el SPN, el gobierno salazarista desarrolló una intensa campaña de propaganda para persuadir a los emigrantes lusos y hacer frente a la contrapropaganda de los opositores en varias ciudades, especialmente en New Bedford y Nueva York. Por primera vez en la historia, un gobernante portugués intentaba mostrarse cerca de sus emigrantes. Las alocuciones radiofónicas, la publicación de artículos elogiosos con el 
dictador en la prensa portuguesa, las celebraciones patrióticas, la participación de las exposiciones internacionales de Nueva York y San Francisco en 1939 y 1940, incluyendo una gira del director del SPN, así como su nombramiento como Honoris Causa en la Fordham University, lo convirtieron en el profeta de un nuevo orden, tal y como fue definido por esta institución académica.

\section{Referencias}

ANTONIO Ferro na California. Jornal Português, p. 4, 7 jul. 1939.

\section{A AUTOPSIA dum imbecil. New Bedford: Aliança Liberal Portuguesa, 1935.}

BAGANHA, Maria Ioannis B. Portuguese emigration to the United States, 18201930. New York: Garland Publishers, 1990.

BANDEIRA, Filomena. Camoesas, João José da Conceição. In: NÓVOA, António (Dir.). Dicionário de educadores portugueses. Porto: Asa, 1988. p. 237-241.

BARROW, Clyde W. (Ed.).Portuguese Americans and contemporary civil culture in Massachusetts. North Dartmouth: Tagus Press, Center for Portuguese Studies and Culture-University of Massachusetts Dartmouth, 2002.

BIANCHI, João A. [Comunicadooficial]. O Progresso, p. 1, 26 nov. 1936.

BIANCHI, João António de. To the portuguese-americans in the U.S. Jornal Português, p. 2, abr. 1940.

CACELLA, José. Benvindo. Diário de Notícias, Lisboa, p. 1, 19 sept. 1933.

CHEGADA a Nova York do comissario geral de Portugal, Sr. Antonio Ferro. Diario de Noticias, Lisboa, p. 1, 17 abr. 1939.

CORREIA, Rui Antunes. Salazar in New Bedford: political readings of Diario de Noticias, the only Portuguese daily newspaper in the United States. In: HOLTON, Kimberly DaCosta;KLIMT, Andrea (Ed.). Community, culture and the makings of identity: Portuguese-Americans along Eastern Seabord. North Dartmouth: Tagus Press, Center for Portuguese Studies and Culture-University of Massachusetts Dartmouth, 2009. p. 227-247.

COSTA, Marques da (Org.). Portugal in New York World's Fair 1939:the official book of the Portuguese representation in the international exhibition of the New York 1939. 1939.

DE LA TORRE GÓMEZ, Hipólito; JIMÉNEZ REDONDO, Juan Carlos (Ed.). Franquismo y salazarismo en el exterior: de la Guerra Civil a las guerras de África. Espacio, Tiempo y Forma: Historia Contemporánea, Madrid, n. 25, 2013. Disponible en: <http://revistas.uned.es/index.php/ETFV/issue/view/767>. Acceso en: 12 jun. 2018. 
DISCURSO de António Ferro no Dia de Portugal na Feira. Diario de Noticias, Lisboa, p. 4, 18 jul. 1939a.

DISCURSO lido pelo Alto Comissário no 'Stand' de Portugal. Jornal Português, p. 5, 7 jul. 1939 b.

DISCURSO pronunciado pelo Exmo. Sr. Antonio Ferro, Comissário Geral de Portugal na Exposição Internacional de Nova York. Diario de Noticias, Lisboa, p. 4, 25 mayo 1939c.

O DR. OLIVEIRA Salazar agradece a mensagem que the foi enviada. Diario de Noticias, Lisboa, p. 1, 18 sept. 1939.

O EMBAIXADOR, Dr. João de Bianchi, é homenageado com um banquete de despedida pela Colonia Portuguesa, en N. York. Diario de Noticias, Lisboa, p. 1-4, 29 jul. 1947.

FERRO, António. Dez anos de política do espírito (1933-1943): Discurso proferido no X aniversário do SPN. Lisboa: Edições do SPN, 1943.

GOULART, Tony (Coord.). Capelinhos: a volcano of synergies: azorean emigration to America. San Jose: Presidência do Governo Regional dos Açores, 2007.

HOMENAGEM a Antonio Ferro. Diario de Noticias, Lisboa, p. 1, 10 jul. 1939.

A IMPORTANTE missão de António Ferro. Diario de Noticias, Lisboa, p. 4, 18 jul. 1939.

JARDIM, Vasco S. A homenagem ao Embaixador de Portugal. Diario de Noticias, Lisboa, 13 oct. 1933. Secção de Newark, p. 3.

LEAL, João. Açores, EUA, Brasil: imigração e etnicidade. Açores: Direção Regional das Comunidades, 2007. Disponible en: $<$ https://run.unl.pt/bitstream/10362/4338/1/A\%C3\%A7ores\%2c\%2bE...pdf>. Acceso en: 12 jun. 2018.

MACEDO, M. O Doutor Oliveira Salazar e a Nação.Diario de Noticias, Lisboa, p. 7, 16 enero 1933.

MATOS, Helena. Salazar: a construção do mito (1928-1933). Lisboa: Temas e Debates, 2010a.

Salazar: a propaganda, 1934-1938. Lisboa: Temas e Debates, $2010 \mathrm{~b}$.

MENDONÇA, Duarte Miguel Barcelos. Da Madeira a New Bedford: um capítulo ignorado da emigração portuguesa nos EUA. Funchal: Direcção Regional dos Assuntos Culturais, 2007.

MENEZES, Filipe Ribeiro de. Salazar: a political biography. New York: Enigma, 2009. 
MENSAGEM do Doutor Oliviera Salazar aos Portugueses na America. Diario de Noticias, Lisboa, p. 4, 18 jul. 1939a.

Jornal Português, p. 4, 7 jul. 1939b.

MOUTINHO, Manuel. A acção social portuguesa. Diario de Noticias, Lisboa, p. 1, 10 nov. 1937a.

Carta aos meus leitores I. Portugal á margem da civilização. Diario de Noticias, Lisboa, p. 1, 7 dic. 1937b.

Carta aos meus leitores II. As nossas tradições liberais. Diario de Noticias, Lisboa, p. 1-2, 16 dic. 1937c.

. Carta aos meus leitores VI. A deslealdade do sr. Lanceta. Diario de Noticias, Lisboa, p. 1-8, 14 enero 1938a.

Carta aos meus leitores X. Um ara da minha graça e uma paródia a uma trova popular. Diario de Noticias, Lisboa, p. 1-5, 10 feb. 1938b.

Carta aos meus leitores XIII. A religião católica na Rússia. Diario de Noticias, Lisboa, p. 1-8, 5 marzo 1938c.

NÚMERO comemorativo dos centenários de Portugal, 1140-1940. Jornal Português, 1940.

PAULO, Heloisa. "Aquí também é Portugal": a colónia portuguesa do Brasil e o Salazarismo. Coimbra: Quarteto, 2000.

PENA, Alberto; MESQUITA, Mário; VICENTE, Paula (Coord.). Emigración e exilio nos Estados Unidos:experiencias de Galicia e Azores. Santiago de Compostela: Consello da Cultura Galega, 2015.

PAP, Leo. The Portuguese-Americans. Boston: Twayne Publishers, 1981. (The Immigrant Heritage of America Series).

PINA, Luiz da Câmara. Dever de Portugal para com as Comunidades Lusíadas da América do Norte: com uma carta-prefácio de sua Eminência o Senhor Cardeal Patriarca de Lisboa. Lisboa: Atelieres Gráficos Bertrand (Irmãos), 1945.

PORTUGAL na Exposição Golden Gate. Jornal Português, p. 1, 10 marzo 1939.

ROSAS, Fernando. Salazar e o poder: a arte de saber durar. Lisboa: Tinta da China, 2012.

SALAZAR é considerado o homem do momento quando a guerra terminar. Jornal Português, p. 1, 7 nov. 1941.

O SENHOR Embaixador de Portugal de visita á California. Jornal Português, p. 1, 16 
abr. 1948.

SILVA, Herculano G. da. Número comemorativo dos centenários de Portugal, 11401640. Jornal Português, p. 3, 28 jun. 1940.

SOARES, Celestino.California and the Portuguese:how the Portuguese helped to build up California: a monograph written for the Golden Gate International Exposition on San Francisco Bay 1939.Lisboa: SPN, 1939.

TEIXEIRA, António C. "Dr. João A. de Bianchi". Jornal Português, p. 1, 15 agosto 1947.

UMA CARTA. O sr. António Eça de Queiroz refuta as acusações contra o governo da ditadura de permitir "maus tratos" aos presos políticos. O Colonial, p. 1-2, 6 sept. 1935.

VALIM, J. C. Salazar, o grande. A União Portuguesa, p. 1, 25 enero 1937.

A VIAGEM triunfal do Embaixador de Portugal. Jornal Português, p. 1, 30 abr. 1948.

A VISITA do ministro de Portugal. Diário de Notícias, Lisboa, p. 2, 20 jul. 1934.

WILLIAMS, Jerry.In Pursuit of Their Dreams: a history of Azorean immigration to the United States. North Dartmouth: Tagus Press, Center for Portuguese Studies and Culture-University of Massachusetts Dartmouth, 2007.

Submetido em: 01.03.2018

Aprovado em: 14.06.2018 